\title{
Overexpression of CXXC5 is a strong poor prognostic factor in $\mathrm{ER}+$ breast cancer
}

\author{
LEI FANG ${ }^{1}$, YU WANG ${ }^{2}$, YANG GAO ${ }^{3}$ and XUEJUN CHEN ${ }^{1}$ \\ ${ }^{1}$ Department of Pathology and Pathophysiology, Jinzhou Medical University, Jinzhou, Liaoning 121000, P.R. China; \\ ${ }^{2}$ Department of Radiology and NFCR Center for Molecular Imaging, Case Western Reserve University, Cleveland, \\ OH 44106-5065, USA; ${ }^{3}$ Department of Oncology, The First Affiliated Hospital of \\ Liaoning Medical University, Jinzhou, Liaoning 121000, P.R. China
}

Received August 3, 2017; Accepted April 26, 2018

DOI: $10.3892 / 01.2018 .8647$

\begin{abstract}
CXXC5 is a newly identified CXXC-type zinc finger family protein, which is encoded by the $C X X C 5$ gene localised to the $5 \mathrm{q} 31.3$ chromosomal region. Previous studies revealed that CXXC5 is associated with various malignant tumours. The aim of the present study was to investigate the prognosis prediction of CXXC5 in different breast cancer subtypes via the Gene Expression Omnibus database and bc-GenExMiner. CXXC5 overexpression was observed as associated with a poor prognosis for oestrogen receptor positive $(\mathrm{ER}+)$ breast cancer. Basal-like breast cancer and triple-negative breast cancer also suggest a poor prognosis, however their CXXC5 expression was low and could not be used as a prognostic factor. The CXXC5 correlated genes and their enriched Gene Ontology (GO) terms were obtained. Among those enriched GO terms, GO:0070062 (extracellular exosome) had the greatest number of associated genes and the associated genes of GO:0000122 (negative regulation of transcription from RNA polymerase II promoter) and GO:0008134 (transcription factor binding) contained CXXC5. These results suggest that overexpression of CXXC5 is a strongly poor prognostic factor in ER+ breast cancer. However, the role of CXXC5 in breast cancer requires further investigation.
\end{abstract}

\section{Introduction}

Breast cancer is one of the most common malignant tumours among women (1). There were precise data from 2012 related to breast cancer incidence and mortality. Across 5 years, from 2008 to 2012, the average incidence rates for white women were the highest, followed by those of black women $(2,3)$. The

Correspondence to: Professor Xuejun Chen, Department of Pathology and Pathophysiology, Jinzhou Medical University, 40 Section 3 Songpo Road, Jinzhou, Liaoning 121000, P.R. China E-mail: thundempest@163.com

Key words: CXXC5, breast cancer, prognosis, biomarker, bc-GenExMiner current 5-year survival rate of primary breast cancer is relatively high, ranging from 80 to $92 \%$ in different populations (4). However, it decreases to $<25 \%$ when the disease becomes metastatic $(4,5)$. The most important factor to improve the survival rate of patients is to find the most effective treatment, which is guided by tumour cell characteristics $(6,7)$. Once a metastatic lesion is found, accurate characterisation of the tumour cells must be obtained at the start of treatment (8); a possible way to do this is the use of biomarkers (9). Currently, a series of different biomarkers, such as tissue markers, genetic markers, serum markers and non-coding RNA $(1,10,11)$, have been found, but it is much more difficult to assess the effectiveness of the targeted treatment or prognosis of the disease. Therefore, we need to find more biomarkers and determine their clinical utility in future research (9).

CXXC finger protein 5 (CXXC5) is a protein encoded by the $C X X C 5$ gene localised to the $5 \mathrm{q} 31.3$ chromosomal region, which is often deleted in myeloid leukaemia (12). Kühnl et al (13) reported that CXXC5 could suppress progression of acute myeloid leukaemia (AML) via inhibiting the Wnt pathway and that downregulation of CXXC5 could predict a better prognosis in AML. The study of Bruserud et al (14) showed that high CXXC5 expression was related to the stem cell signature of AML that has a bad prognostic impact. We know that $17 \beta$-oestradiol (E2) plays an important role in the homeodynamic regulation of breast tissue functions, and the oestrogen receptor $(\mathrm{ER} \alpha)$ is the primary transcript expressed in breast tissue. Yasar et al (15) reported that E2-ER $\alpha$ could regulate the expression of CXXC5. Therefore, we knew that there was a certain relationship between CXXC5 and breast cancer. Knappskog et al (16) reported that the overexpression of CXXC5 was significantly associated with a bad prognosis in breast cancer. However, the prognostic implications of CXXC5 expression in breast cancers of different molecular types remain unclear. In our study, we used Breast Cancer Gene-Expression Miner v4.0 (bc-GenExMiner v4.0, bcgenex. centregauducheau.fr/BC-GEM/GEM-Accueil.php?js=1) (17), a database that includes a total of 5,861 patients, as the main tool to analyse the role of CXXC5 expression in different breast cancer subtypes. We aimed to show that CXXC5 expression predicts the prognosis of different breast cancer subtypes. 


\section{Materials and methods}

GEO data analysis. We obtained the dataset of GDS5666 (18) from Gene Expression Omnibus (GEO; https://www.ncbi.nlm. nih.gov/geo/) (19) and analysed it using the Data Analysis Tools of DATASET BROWSER in GEO. Probes of A_51_P234788 (ID_REF) and A_52_P633393 (ID_REF) represented the CXXC5 gene in the platform of GPL7202. We obtained 2 sets of CXXC5 mRNA expression values from these probes. We used the average value of each sample's CXXC5 mRNA expression as the expression value for that sample.

Bioinformatics analysis by bc-GenExMiner v4.0. Using bc-GenExMiner v4.0, we conducted CXXC5 expression analysis, prognostic analysis for CXXC5 through univariate Cox analysis and Kaplan-Meier curve analysis, and gene correlation analysis for CXXC5. Then, we obtained the gene ontology (GO) term results through gene correlation exhaustive analysis. The database of bc-GenExMiner v4.0 had 36 datasets, including a total of 5,861 patients. There were 21 datasets including 3,524 patients for CXXC5 expression analysis and gene correlation analysis among a total of 36 datasets. A total of 3,472 patients from 21 datasets were used for prognostic analysis for CXXC5 with any nodal status, any ER status and any event (AE).

Statistical analysis. In the comparison of CXXC5 expression in primary and metastatic tumours, we used SPSS version 19.0 (IBM SPSS, Armonk, NY, USA) as the software for statistical analysis. Two-tailed unpaired t-tests were used for statistical comparisons. Data are represented as the means \pm standard error of the mean. $\mathrm{P}<0.05$ was considered significant. In other research, the statistical analysis for comparison of CXXC5 expression according to ER and Kaplan-Meier survival curves and univariate Cox analysis was performed by bc-GenExMiner v4.0. Box and whiskers plots are displayed, along with Dunett-Tukey-Kramer's test and Welch's t-test for every possible clinical criteria for $C X X C 5$ gene.

\section{Results}

CXXC5 expression is increased in 4T1-derived metastatic cancer compared to primary cancer. We observed that the expression values of CXXC5 were higher in 4T1-derived metastatic populations than in primary cancers (Fig. 1A). Then, we used bc-GenExMiner v4.0 to determine that CXXC5 upregulation with metastatic relapse (MR) or AE was associated with a poor prognosis of breast cancer (Fig. 1B and C). In the PAM50 breast cancer subtypes, the basal-like subtype had the lowest CXXC5 expression, and CXXC5 expression of luminal tumours was higher than in other types (Fig. 1D).

High level of CXXC5 is a poor prognostic factor in oestrogen receptor positive $(E R+)$ breast cancer. The impact of CXXC5 in breast cancer was considered robust because there were 10 significant results $(\mathrm{P}<0.05)$ among the 18 given results (Table I). We determined that the high level of CXXC5 expression is associated with poor prognosis of breast cancer with $\mathrm{Nm} / \mathrm{ER}+/ \mathrm{AE}, \mathrm{Nm} / \mathrm{ER}+/ \mathrm{MR}, \mathrm{N}+$ /ER+/AE, N-/ER+/MR, $\mathrm{N}+$ /ER+/MR, Nm/ERm/MR, Nm/ERm/AE, N+/ERm/AE,
$\mathrm{N}+$ /ER-/AE and N-/ER+/AE through CXXC5 univariate Cox analysis (Table I). In particular, all breast cancer patients with ER+ status had a poor prognosis. CXXC5 expression was significantly higher in ER+ breast cancer than in ER- breast cancer (Fig. 2A). Using the Kaplan-Meier curve, we ascertained that high CXXC5 expression predicted significantly poor AE-free survival in $\mathrm{Nm} / \mathrm{ER}+$ status ( $\mathrm{HR}=1.50 ; 95 \% \mathrm{CI}, 1.31-1.73 ; \mathrm{P}<0.0001)$ (Fig. 2B), MR-free survival in Nm/ER+ status (HR=1.70; 95\% CI, 1.37-2.10; $\mathrm{P}<0.0001$ ) (Fig. 2C), AE-free survival in $\mathrm{N}+/ \mathrm{ER}+$ status (HR=1.51; 95\% CI, 1.21-1.87; P=0.0002) (Fig. 2D), MR-free survival in $\mathrm{N}-/ \mathrm{ER}+$ status $(\mathrm{HR}=1.56$; $95 \% \mathrm{CI}, 1.06-2.27$; $\mathrm{P}=0.0228$ ) (Fig. 2E) and MR-free survival in $\mathrm{N}+/ \mathrm{ER}+$ status (HR=1.59; 95\% CI, 1.16-2.20; $\mathrm{P}=0.0042$ ) (Fig. 2F). However, CXXC5 expression could not predict AE-free survival in $\mathrm{N}-/$ ER+ status $(\mathrm{P}=0.0763)$ (Fig. 2G).

Basal-like breast cancer and/or TNBC prognostic analysis for CXXC5. The basal-like breast cancer had lower CXXC5 expression than other subtypes (Fig. 1D). However, basal-like breast cancer could predict bad prognosis, as $75-80 \%$ of the triple-negative breast cancers (TNBC) belonged to the group of basal-like breast cancer (20). High levels of CXXC5 expression could predict a bad prognosis in TNBC with MR via CXXC5 univariate Cox analysis (basal-like and/or TNBC) but not in the other group (Tables II and III). However, CXXC5 expression was not associated with prognosis of TNBC with MR through the Kaplan-Meier curve analysis (Fig. 3A). Consistent with the results of CXXC5 univariate Cox analysis (basal-like and/or TNBC), CXXC5 expression was not associated with the prognosis of breast cancer in the other groups (Fig. 3B-F).

Correlated genes with CXXC5. We obtained the correlated genes with CXXC5 in breast cancer through gene correlation exhaustive analysis. Table IV shows the top 10 best positive/negative correlations with CXXC5. Then, we obtained the GO enrichments of the correlated genes with CXXC5 via GO analysis of bc-GenExMiner v4.0 (Table V). Among them, GO:0070062 (extracellular exosome) had the most associated genes, and the associated genes of both GO:0000122 (negative regulation of transcription from RNA polymerase II promoter) and GO:0008134 (transcription factor binding) contained CXXC5.

\section{Discussion}

CXXC5 is a newly identified CXXC-type zinc finger family protein (21), which is encoded by the $C X X C 5$ gene localised to the $5 \mathrm{q} 31.3$ chromosomal region (12). Previous studies showed that CXXC5 was related to AML, myelodysplastic syndromes, human malignant peripheral nerve sheath tumours, prostate cancer, breast cancer, thyroid cancers and metastatic melanomas (16,22-25). Knappskog et al (16) used three independent public microarray datasets, including 599 patients from GEO, to find that CXXC5 was a bad prognostic factor in breast cancer. However, they did not study the effects of CXXC5 on various subtypes in breast cancer.

In our study, using the dataset of GDS5666 from GEO, we found that the expression of CXXC5 was higher in 4T1-derived metastatic populations than in primary breast cancers. 
Table I. CXXC5 univariate Cox analysis.

\begin{tabular}{|c|c|c|c|c|c|c|c|c|}
\hline No. & Nodal status & ER status & Event status & P-value & Hazard ratio & $95 \% \mathrm{CI}$ & No. patients & No. events \\
\hline 1 & Nm & $\mathbf{E R +}$ & $\mathbf{A E}$ & $<0.0001$ & 1.31 & $1.22-1.42$ & 2,461 & 845 \\
\hline 2 & $\mathrm{Nm}$ & ER+ & MR & $<0.0001$ & 1.53 & 1.34-1.74 & 1,450 & 355 \\
\hline 3 & $\mathbf{N}+$ & ER+ & $\mathbf{A E}$ & 0.0001 & 1.30 & 1.14-1.48 & 846 & 348 \\
\hline 4 & N- & ER+ & MR & 0.0002 & 1.61 & $1.25-2.08$ & 542 & 113 \\
\hline 5 & N+ & ER+ & MR & 0.0009 & 1.35 & 1.13-1.61 & 475 & 156 \\
\hline 6 & Nm & ERm & MR & 0.0027 & 1.15 & $1.05-1.26$ & 2,017 & 539 \\
\hline 7 & Nm & ERm & $\mathbf{A E}$ & 0.0057 & 1.09 & 1.02-1.15 & 3,472 & 1,260 \\
\hline 8 & N+ & ERm & $\mathbf{A E}$ & 0.0162 & 1.13 & $1.02-1.25$ & 1,127 & 503 \\
\hline 9 & N+ & ER- & $\mathbf{A E}$ & 0.0201 & 1.26 & $1.04-1.53$ & 278 & 155 \\
\hline 10 & N- & ER+ & $\mathbf{A E}$ & 0.0347 & 1.15 & 1.01-1.32 & 924 & 277 \\
\hline 11 & $\mathrm{~N}+$ & ERm & MR & 0.0540 & 1.15 & $1.00-1.32$ & 612 & 224 \\
\hline 12 & $\mathrm{~N}+$ & ER- & MR & 0.0540 & 1.32 & $1.00-1.75$ & 135 & 68 \\
\hline 13 & $\mathrm{Nm}$ & ER- & $\mathrm{AE}$ & 0.0784 & 1.10 & $0.99-1.22$ & 972 & 406 \\
\hline 14 & $\mathrm{Nm}$ & ER- & MR & 0.1103 & 1.13 & $0.97-1.32$ & 547 & 181 \\
\hline 15 & $\mathrm{~N}-$ & ERm & MR & 0.1563 & 1.12 & $0.96-1.32$ & 762 & 167 \\
\hline 16 & $\mathrm{~N}-$ & ER- & MR & 0.5774 & 1.08 & $0.82-1.42$ & 205 & 53 \\
\hline 17 & $\mathrm{~N}-$ & ER- & $\mathrm{AE}$ & 0.7933 & 0.98 & $0.81-1.17$ & 361 & 118 \\
\hline 18 & $\mathrm{~N}-$ & ERm & $\mathrm{AE}$ & 0.8053 & 0.99 & 0.89-1.09 & 1,306 & 399 \\
\hline
\end{tabular}

CXXC5, CXXC finger protein 5; ER, estrogen receptor; CI, confidence interval; m, mixed; +, positive; -, negative; AE, any event; MR, metastatic relapse. Bold text indicates $\mathrm{P}<0.05$.

A

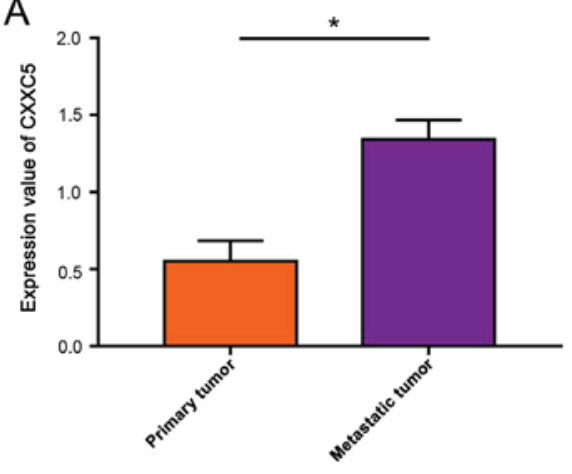

c

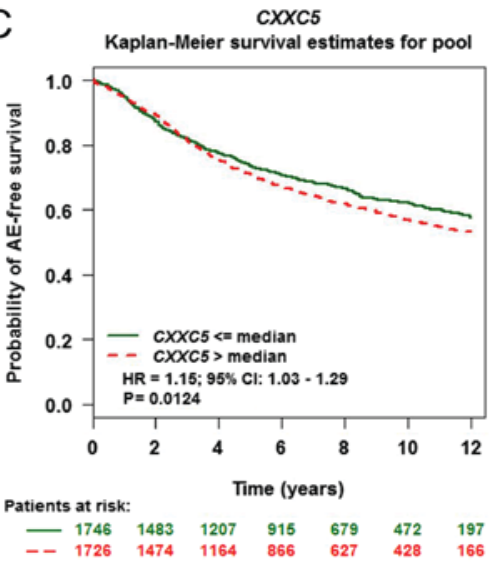

B

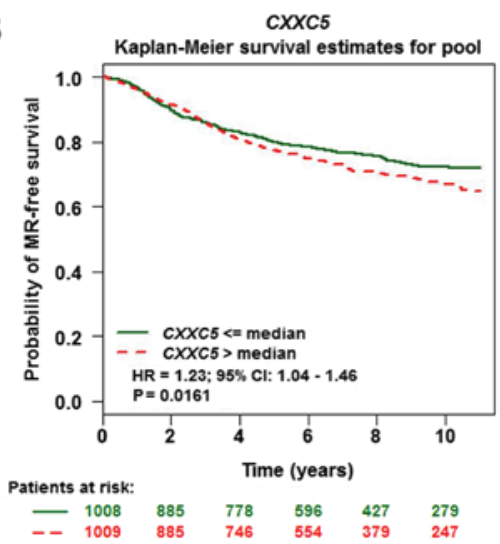

$\mathrm{D}$

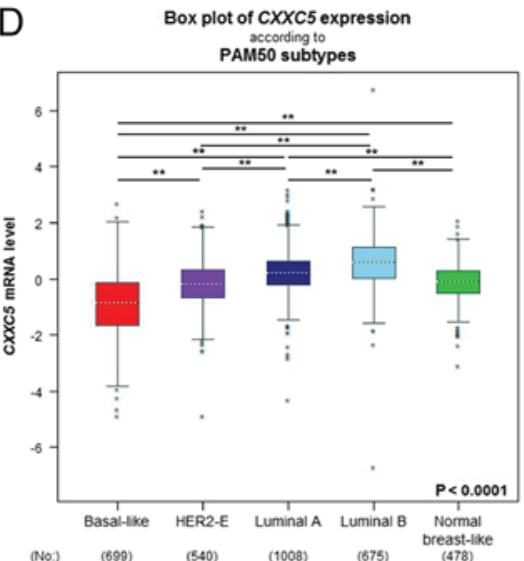

Figure 1. CXXC5 expression is increased in 4T1-derived metastatic cancer compared to primary cancer. (A) Expression value of CXXC5 in 4T1-derived metastatic cancer, compared with primary breast cancer, through data analysis of GDS5666. Student's t-test; "P $<0.05$. The Kaplan-Meier curve of breast cancer with (B) MR-free (C) and AE-free CXXC5 expression. Data were obtained and analysed by using bc-GenExMiner v4.0. (D) Box plot of CXXC5 mRNA expression according to PAM50 subtype in bc-GenExMiner v4.0. Dunnett-Tukey-Kramer's test; ${ }^{* *} \mathrm{P}<0.0001$. CXXC5, CXXC finger protein 5; MR, metastatic relapse; AE, any event. 
Table II. Univariate Cox analysis (basal-like and/or TNBC) for CXXC5 with MR.

\begin{tabular}{lccccr}
\hline Population & P-value & HR & $95 \%$ CI & No. patients & No. MR \\
\hline Basal-like & 0.8288 & 1.02 & $0.84-1.24$ & 375 & 109 \\
TNBC & $\mathbf{0 . 0 3 6 9}$ & $\mathbf{1 . 6 6}$ & $\mathbf{1 . 0 3 - 2 . 6 7}$ & $\mathbf{8 0}$ & $\mathbf{1 8}$ \\
Basal-like + TNBC & 0.7465 & 1.24 & $0.34-4.54$ & 45 & 5
\end{tabular}

CXXC5, CXXC finger protein 5; TNBC, triple-negative breast cancer; CI, confidence interval; MR, metastatic relapse. Bold text indicates $\mathrm{P}<0.05$.

Table III. Univariate Cox analysis (basal-like and/or TNBC) for CXXC5 with AE.

\begin{tabular}{lccccc}
\hline Population & P-value & HR & $95 \%$ CI & No. patients & No. AE \\
\hline Basal-like & 0.8185 & 0.99 & $0.87-1.12$ & 690 & 251 \\
TNBC & 0.4321 & 1.12 & $0.84-1.50$ & 194 & 58 \\
Basal-like + TNBC & 0.7343 & 0.92 & $0.55-1.52$ & 118 & 24 \\
\hline
\end{tabular}

CXXC5, CXXC finger protein 5; CI, confidence interval; m, mixed; AE, any event; TNBC, triple-negative breast cancer.

Therefore, CXXC5 might be associated with metastasis. Then, we used expression analysis of bc-GenExMiner v4.0 to find that the expression of CXXC5 was significantly different in PAM subtypes. We established that the high level of CXXC5 expression is associated with poor prognosis of ER+ breast cancer through CXXC5 univariate Cox analysis and Kaplan-Meier curve analysis of bc-GenExMiner v4.0. These results propose CXXC5 as a biomarker and potential therapeutic target in ER+ breast cancer. Although basal-like breast cancer and TNBC could predict bad prognosis, their CXXC5 expression was low. In addition, CXXC5 could not predict their prognosis. Finally, we obtained the CXXC5 correlated genes and enriched GO terms of those genes through gene correlation exhaustive analysis of bc-GenExMiner v4.0. Among those enriched GO terms, GO:0070062 (extracellular exosome) had the most associated genes, and the associated genes of both GO:0000122 (negative regulation of transcription from RNA polymerase II promoter) and GO:0008134 (transcription factor binding) contained CXXC5. These GO terms can guide new investigations into understanding the mechanisms of CXXC5 in breast cancer and propose new treatments for ER+ breast cancer.

There is a limitation to the present study. The mechanism of CXXC5 in breast cancer requires further investigation via in vitro and in vivo experiments.

In conclusion, we determined that overexpression of CXXC5 was a strongly poor prognostic factor in ER+ breast cancer through the tools of bc-GenExMiner V4.0 based on a database including a total of 5,861 patients. This means that regardless of the clinical stage of breast cancer, high expression of CXXC5 in patients predicts that the disease is more significantly invasive. As is known, gene expression can be measured in many ways. We hope that measuring the expression of CXXC5 may become a routine inspection to assess the prognosis of breast cancer in different patients. In this way, early intervention and treatment could be used, and the survival rate of patients could improve. However, the pathways
Table IV. Top 10 best positive/negative correlated genes with CXXC5.

\begin{tabular}{lcrr}
\hline $\begin{array}{l}\text { Gene } \\
\text { symbol }\end{array}$ & $\begin{array}{c}\text { Pearson's correlation } \\
\text { coefficient }\end{array}$ & P-value & $\begin{array}{r}\text { No. of } \\
\text { patient }\end{array}$ \\
\hline Positive & & & \\
correlation & & & \\
FKBP9P1 & 0.5858 & $<0.0001$ & 214 \\
LOC149401 & 0.5849 & $<0.0001$ & 155 \\
LOC100288069 & 0.5806 & $<0.0001$ & 214 \\
ACTG1P20 & 0.5784 & $<0.0001$ & 326 \\
CA12 & 0.5474 & $<0.0001$ & 3,524 \\
FOXA1 & 0.5377 & $<0.0001$ & 3,524 \\
GATA3 & 0.5338 & $<0.0001$ & 3,524 \\
AGR2 & 0.5287 & $<0.0001$ & 3,524 \\
PRINS & 0.5245 & $<0.0001$ & 155 \\
AGR3 & 0.5235 & $<0.0001$ & 3,023
\end{tabular}

Negative

correlation

$\begin{array}{llll}\text { FLJ44715 } & -0.8160 & <0.0001 & 155 \\ \text { LOC100507412 } & -0.8069 & <0.0001 & 155 \\ \text { LOC100133683 } & -0.7873 & <0.0001 & 155 \\ \text { LOC729461 } & -0.7741 & <0.0001 & 155 \\ \text { LOC728543 } & -0.7698 & <0.0001 & 155 \\ \text { CEP170P1 } & -0.6993 & <0.0001 & 155 \\ \text { LOC729324 } & -0.6529 & <0.0001 & 155 \\ \text { CEP295NL } & -0.6524 & <0.0001 & 155 \\ \text { LOC653739 } & -0.5980 & <0.0001 & 155 \\ \text { LOC100507637 } & -0.5718 & <0.0001 & 155\end{array}$

CXXC5, CXXC finger protein 5. 

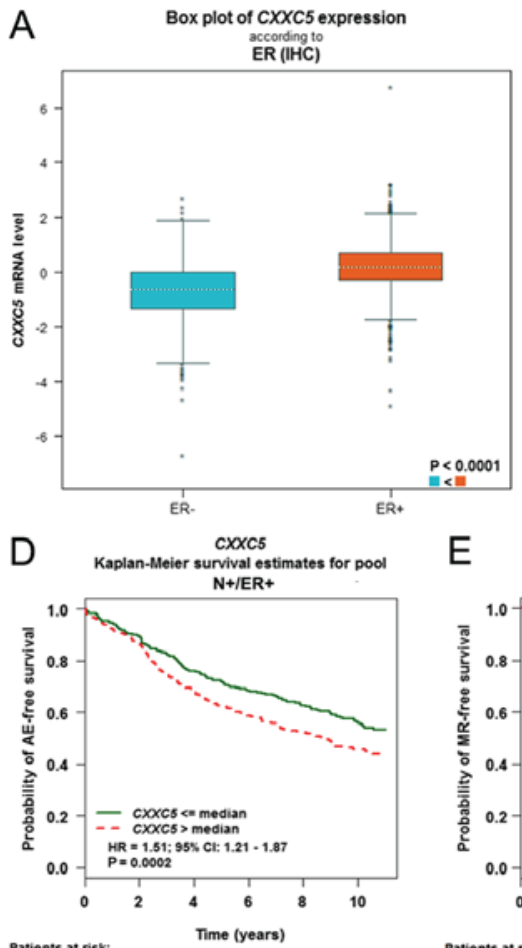

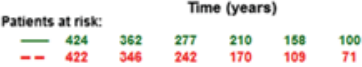

B

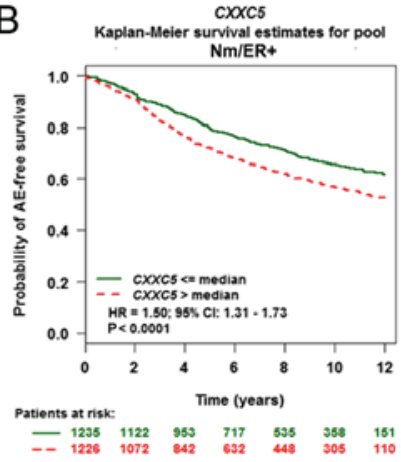

C Kaplan-Meier survival estimates for pool

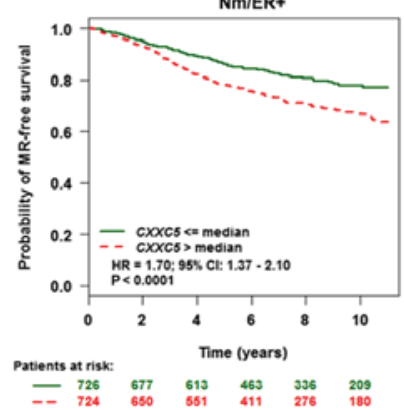

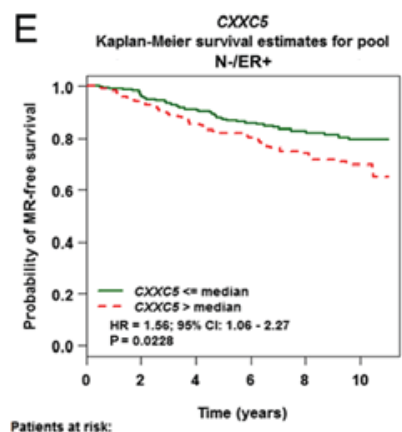

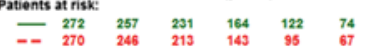

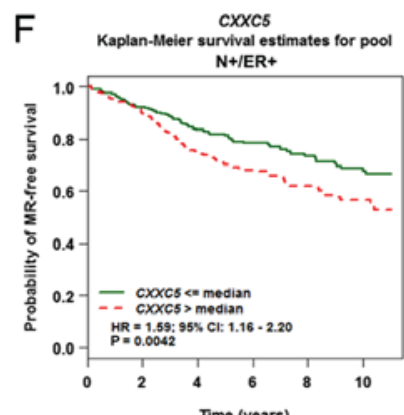

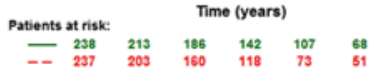

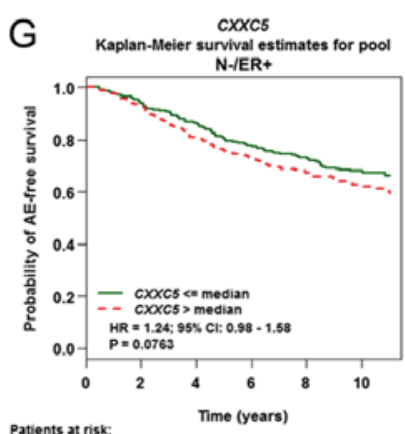

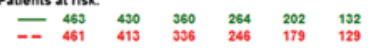

Figure 2. High levels of CXXC5 is a poor prognostic factor in ER+ breast cancer. (A) Box plot of CXXC5 mRNA expression according to ER. The Kaplan-Meier curves of breast cancer with (B) Nm/ER+/AE, (C) Nm/ER+/MR, (D) N+/ER+/AE, (E) N-/ER+/MR, (F) N+/ER+/MR and (G) N-/ER+/AE. All data were obtained and analysed by using bc-GenExMiner v4.0. N, nodal status; ER, oestrogen receptor status; +, positive; -, negative; m, mixed.

A CXXC5, Kaplan-Meier survival estimates (Pool)
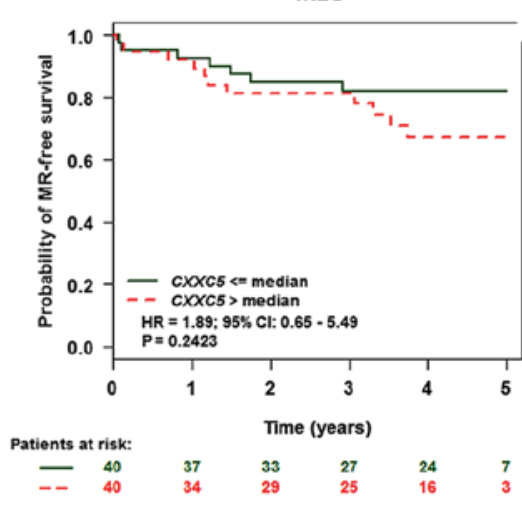

D CXXC5, Kaplan-Meier survival estimates (Pool)

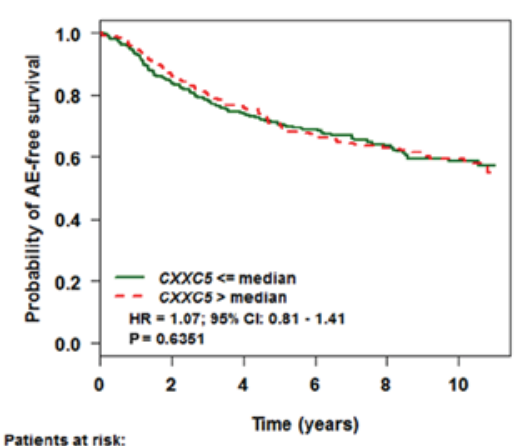

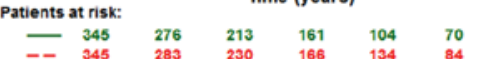

B CXXc5, Kaplan-Meier survival estimates (Pool)

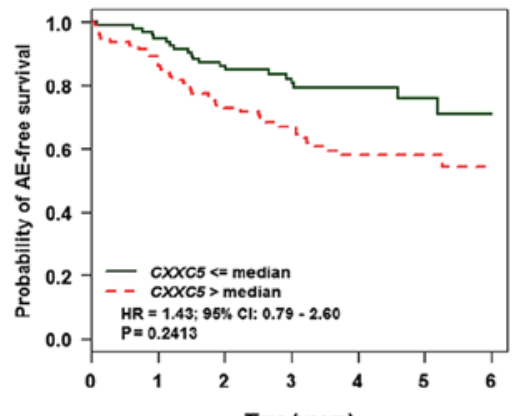

Patients at risk: Time (years)
C CXXC5, Kaplan-Meier survival estimates (Pool)

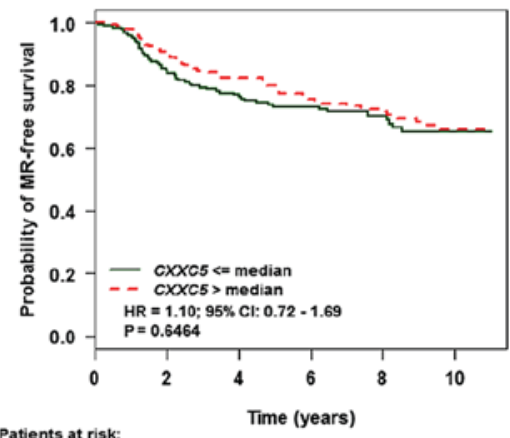

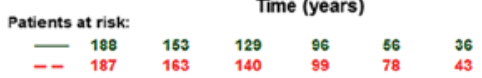

E CXXC5, Kaplan-Meier survival estimates (Pool) $\mathrm{F}$

F $\quad$ CXXC5, Kaplan-Meier survival estimates (Pool)
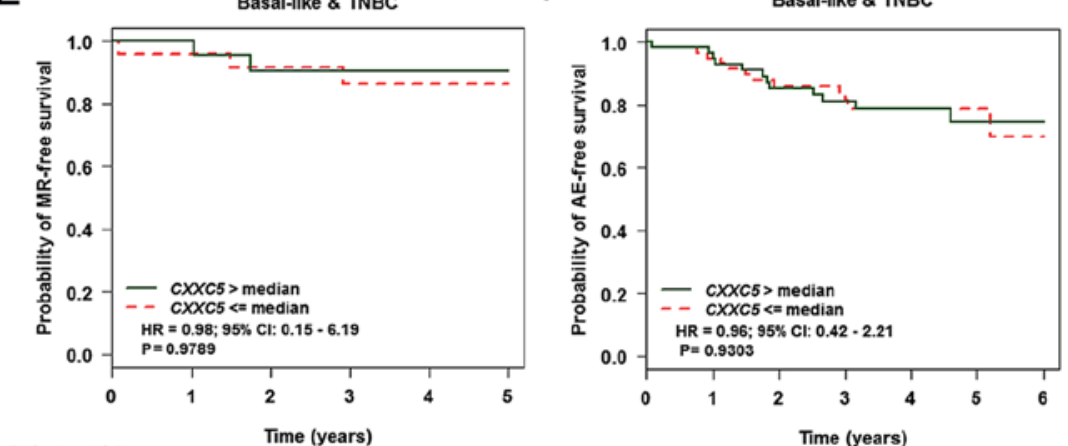

Patients at risk: Time (years)

Patients at risk: at risk: Time (years)

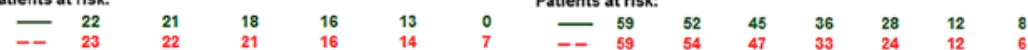

Figure 3. Expression of CXXC5 could not predict the prognosis of basal-like breast cancer and/or TNBC. The Kaplan-Meier curves of TNBC with (A) MR and (B) AE, basal-like breast cancer with (C) MR and (D) AE and basal-like and TNBC with (E) MR and (F) AE. All data were obtained and analysed by using bc-GenExMiner v4.0. TNBC, triple-negative breast cancer; MR, metastatic relapse; AE, any event. 


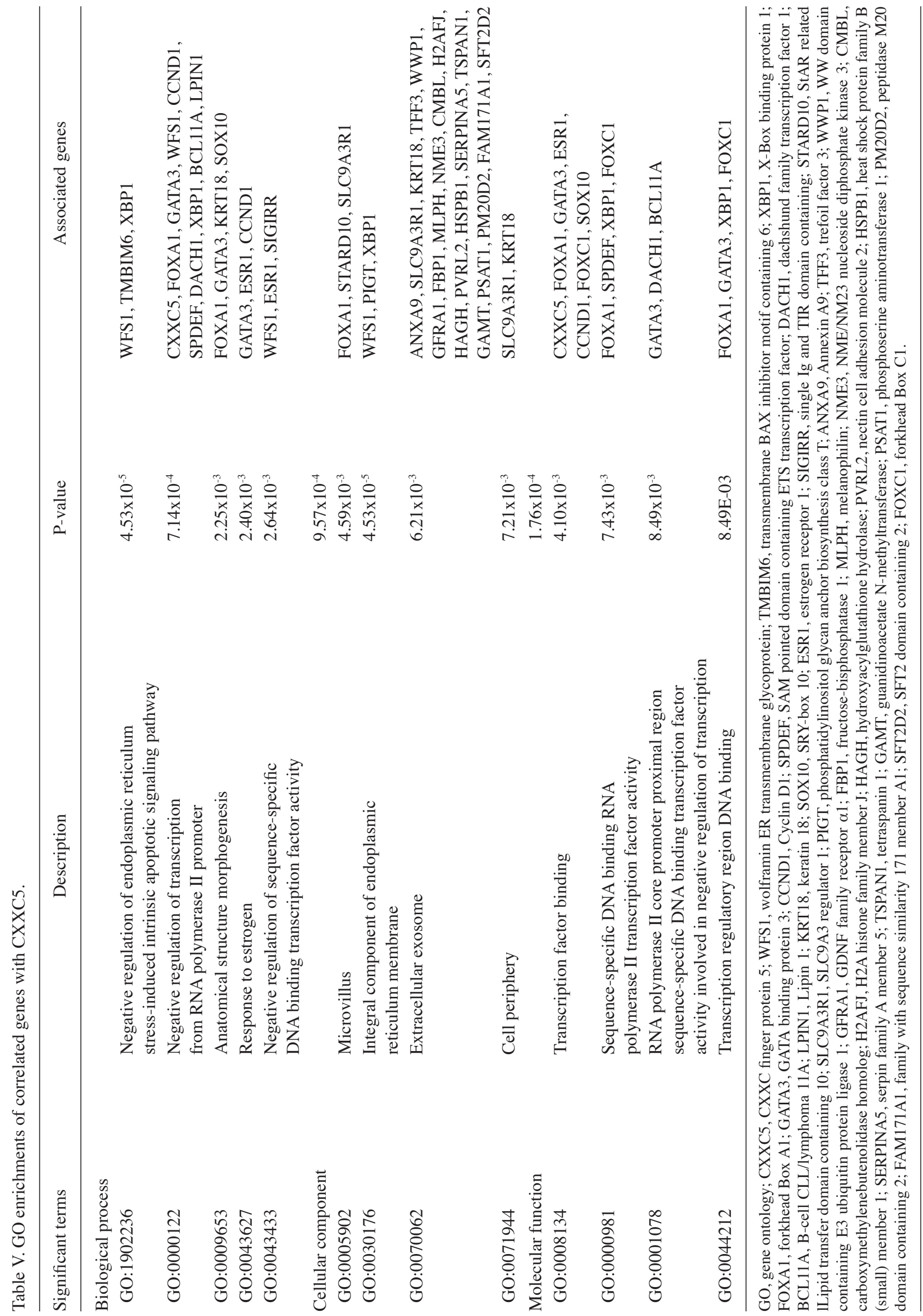


of CXXC5 in breast cancer require further investigation. If in-depth research is conducted, we may find the pathways of CXXC5 in breast cancer, and then CXXC5 can be utilized as a potential therapeutic target.

\section{Acknowledgements}

Not applicable.

\section{Funding}

No funding was received.

\section{Availability of data and materials}

The data that support the findings of this study are available from GEO database (GDS5666; www.ncbi.nlm.nih. gov/geo/) and Breast Cancer Gene-Expression Miner (bcgenex. centregauducheau.fr/BC-GEM/GEM-Accueil.php?js=1).

\section{Authors' contributions}

LF, YW and XC conceived and designed the study. LF and YG analyzed and interpreted the data. LF and YW were the contributors in writing the manuscript. All authors read and approved the final manuscript.

\section{Ethics approval and consent to participate}

Not applicable.

\section{Consent for publication}

Not applicable.

\section{Competing interests}

The authors declare that they have no competing interests.

\section{References}

1. Donepudi MS, Kondapalli K, Amos SJ and Venkanteshan P: Breast cancer statistics and markers. J Cancer Res Ther 10: 506-511, 2014

2. DeSantis CE, Fedewa SA, Goding Sauer A, Kramer JL, Smith RA and Jemal A: Breast cancer statistics, 2015: Convergence of incidence rates between black and white women. CA Cancer J Clin 66: 31-42, 2016.

3. DeSantis CE, Siegel RL, Sauer AG, Miller KD, Fedewa SA, Alcaraz KI and Jemal A: Cancer statistics for African Americans, 2016: Progress and opportunities in reducing racial disparities. CA Cancer J Clin 66: 290-308, 2016.

4. Siegel RL, Miller KD and Jemal A: Cancer statistics, 2015. CA Cancer J Clin 65: 5-29, 2015.

5. Ferlay J, Soerjomataram I, Dikshit R, Eser S, Mathers C, Rebelo M, Parkin DM, Forman D and Bray F: Cancer incidence and mortality worldwide: Sources, methods and major patterns in GLOBOCAN 2012. Int J Cancer 136: E359-E386, 2015.

6. Ufen MP, Köhne CH, Wischneswky M, Wolters R Novopashenny I, Fischer J, Constantinidou M, Possinger K and Regierer AC: Metastatic breast cancer: Are we treating the same patients as in the past? Ann Oncol 25: 95-100, 2014.

7. Zervoudis S, Iatrakis G, Tomara E, Bothou A, Papadopoulos G and Tsakiris G: Main controversies in breast cancer. World J Clin Oncol 5: 359-373, 2014.
8. Marino N, Woditschka S, Reed LT, Nakayama J, Mayer M, Wetzel M and Steeg PS: Breast cancer metastasis: Issues for the personalization of its prevention and treatment. Am J Pathol 183: 1084-1095, 2013

9. Nalejska E, Mączyńska E and Lewandowska MA: Prognostic and predictive biomarkers: Tools in personalized oncology. Mol Diagn Ther 18: 273-284, 2014.

10. Gasparri ML, Casorelli A, Bardhi E, Besharat AR, Savone D, Ruscito I, Farooqi AA, Papadia A, Mueller MD, Ferretti E and Benedetti Panici P: Beyond circulating microRNA biomarkers: Urinary microRNAs in ovarian and breast cancer. Tumor Biol 39: 1010428317695525, 2017.

11. Ye N, Wang B, Quan ZF, Cao SJ, Wen XT, Huang Y, Huang XB, Wu R, Ma XP and Yan QG: Functional roles of long non-coding RNA in human breast cancer. Asian Pac J Cancer Prev 15: 5993-5997, 2014.

12. Pendino F, Nguyen E, Jonassen I, Dysvik B, Azouz A, Lanotte M, Ségal-Bendirdjian E and Lillehaug JR: Functional involvement of RINF, retinoid-inducible nuclear factor (CXXC5), in normal and tumoral human myelopoiesis. Blood 113: 3172-3181, 2009.

13. Kühnl A, Valk PJ, Sanders MA, Ivey A, Hills RK, Mills KI, GaleRE, Kaiser MF, Dillon R, Joannides M, et al: Downregulation of the Wnt inhibitor CXXC5 predicts a better prognosis in acute myeloid leukemia. Blood 125: 2985-2994, 2015.

14. Bruserud $\varnothing$, Reikvam H, Fredly H, Skavland J, Hagen KM, van Hoang TT, Brenner AK, Kadi A, Astori A, Gjertsen BT and Pendino F: Expression of the potential therapeutic target CXXC5 in primary acute myeloid leukemia cells-high expression is associated with adverse prognosis as well as altered intracellular signaling and transcriptional regulation. Oncotarget 6: 2794-2811, 2015.

15. Yasar P, Ayaz G and Muyan M: Estradiol-estrogen receptor $\alpha$ mediates the expression of the CXXC5 gene through the estrogen response element-dependent signaling pathway. Sci Rep 6: 37808, 2016.

16. Knappskog S, Myklebust LM, Busch C, Aloysius T, Varhaug JE, Lønning PE, Lillehaug JR and Pendino F: RINF (CXXC5) is overexpressed in solid tumors and is an unfavorable prognostic factor in breast cancer. Ann Oncol 22: 2208-2215, 2011.

17. Jézéquel P, Campone M, Gouraud W, Guérin-Charbonnel C, Leux C, Ricolleau G and Campion L: bc-GenExMiner: An easy-to-use online platform for gene prognostic analyses in breast cancer. Breast Cancer Res Treat 131: 765-775, 2012.

18. Tabariès S, Ouellet V, Hsu BE, Annis MG, Rose AA, Meunier L, Carmona E, Tam CE, Mes-Masson AM and Siegel PM: Granulocytic immune infiltrates are essential for the efficient formation of breast cancer liver metastases. Breast Cancer Res 17: 45, 2015.

19. Barrett T, Wilhite SE, Ledoux P, Evangelista C, Kim IF, Tomashevsky M, Marshall KA, Phillippy KH, Sherman PM, Holko M, et al: NCBI GEO: Archive for functional genomics data sets-update. Nucleic Acids Res 41 (Database Issue): D991-D995, 2013.

20. Badowska-Kozakiewicz AM and Budzik MP: Immunohistochemical characteristics of basal-like breast cancer. Contemp Oncol (Pozn) 20: 436-443, 2016.

21. Zhang M, Wang R, Wang Y, Diao F, Lu F, Gao D, Chen D, Zhai $\mathrm{Z}$ and Shu H: The CXXC finger 5 protein is required for DNA damage-induced p53 activation. Sci China C Life Sci 52: 528-538, 2009

22. Astori A, Fredly H, Aloysius TA, Bullinger L, Mansat-De Mas V, de la Grange P, Delhommeau F, Hagen KM, Récher C, Dusanter-Fourt I, et al: CXXC5 (retinoid-inducible nuclear factor, RINF) is a potential therapeutic target in high-risk human acute myeloid leukemia. Oncotarget 4: 1438-1448, 2013.

23. Stoddart A, QianZ,Fernald AA,Bergerson RJ, Wang J, Karrison T, Anastasi J, Bartom ET, Sarver AL, McNerney ME, et al: Retroviral insertional mutagenesis identifies the del(5q) genes, CXXC5, TIFAB and ETF1, as well as the Wnt pathway, as potential targets in del(5q) myeloid neoplasms. Haematologica 101: e232-e236, 2016.

24. Cui Z, Shen Y, Chen KH, Mittal SK, Yang JY and Zhang G: KANK1 inhibits cell growth by inducing apoptosis though regulating CXXC5 in human malignant peripheral nerve sheath tumors. Sci Rep 7: 40325, 2017.

25. Bettin A, Reyes I and Reyes N: Gene expression profiling of prostate cancer-associated genes identifies fibromodulin as potential novel biomarker for prostate cancer. Int J Biol Markers 31: e153-e162, 2016

This work is licensed under a Creative Commons Attribution-NonCommercial-NoDerivatives 4.0 International (CC BY-NC-ND 4.0) License. 